DRAFT of the article submitted to Asian Anthropology and published in 2019:

Kavedžija, I., 2019. "I move my hand and then I see it": sensing and knowing with young artists in Japan. Asian Anthropology, pp.1-16. https://doi.org/10.1080/1683478X.2019.1627747

\title{
"I move my hand and then I see it": Sensing and knowing with young artists in Japan
}

\section{Dr Iza Kavedžija}

University of Exeter

i.kavedzija@exeter.ac.uk

Iza Kavedžija is a Lecturer in Anthropology at the University of Exeter. Her research interests include meaning in life, motivation, life choices, wellbeing, aging and the life course. She specializes in the anthropology of Japan, and her doctoral research, at the University of Oxford, examined the construction of meaning in life and the experience of aging among older people in Osaka. A monograph based on this work, entitled Making Meaningful Lives: Tales from Aging Japan, is forthcoming with the University of Pennsylvania Press. 


\title{
"I move my hand and then I see it": Sensing and knowing with young artists in Japan
}

\author{
Abstract \\ When asked to reflect on their own creative practice, contemporary artists in Osaka \\ would frequently invoke images of movement. In lieu of a preformed mental image or \\ plan, they would emphasise the processual and emergent nature of creating a work of \\ art and the importance of moving one's body, likening the gradual and meandering \\ nature of their understanding to a "path." At the same time, they would often \\ compare their own lives to a path, albeit one with a far less visible endpoint than that \\ which lay ahead of practitioners of the traditional Japanese arts. Along this particular \\ life path, one must move without a clear idea of where one is headed; the path is laid \\ down as one moves along it. "Feeling with the world" and sensing in collaboration \\ with others, emerges as a mode of knowing.
}

Keywords: Japan, artists, art-work, imagination, agency, the body

\footnotetext{
The imaginative aura is anticipatory, independently so, as when one begins a thought, a sentence, a drawing, a musical composition without knowing and yet knowing, indeed with some certainty, how will it end, that it will come to some sort of fruition even if that fruition is a failure. It can be related to...those indefinable, inner movements of consciousness that appear and disappear so rapidly that we barely perceive them, despite the often intense sensations they produce in us. (Crapanzano 2003, 20).
}

In his book on Imaginative Horizons (2010) Crapanzano describes his interest in the imagination as giving attention to that which is always indeterminate or vague in human experience: "that 
dimension of experience that insofar as it resists articulation, indeed disappears with articulation, has in fact been ignored" (ibid., 18). In describing this place, he resorts to an image of a flowing river from William James - no amount of pots, barrels or vessels, even if submerged in the river itself, could effectively capture the river: discrete as they are, despite containing the water, they do not contain its flow. The processual and open-ended quality of the imaginative recur in anthropological discussions of imagination. The vagueness and resistance to articulation resonate with recent discussions of affect, which has notably (if somewhat problematically) understood it as a sensation or a feeling that unbeknownst to the subject moves through it and as such is not mediated by consciousness or cognitive processes, as Spinoza pointed out (Navaro-Yashin 2012, 168).

While explicitly refusing to offer a theory of imagination, Crapanzano circles the theme in a way that resembles swarming thoughts. He moves away from the image, the dominance of which is culturally and historically peculiar, to include a broad range of senses such as smell, taste and sound, and those of a moving body - kinaesthetic or proprioceptive and their various entanglements: "The imagination may simply refer to an organizing principle or faculty: one which conjoins the logically and conventionally disparate" (Crapanzano ibid, 23). In this way, imagination can be understood as the entwinement of the senses and affect.

In this article I discuss two imaginative practices or creative processes: the process of creating an artwork; and the process of composing a life as a young artist in contemporary Japan. In the accounts of the young artists in Osaka with whom I worked, both these processes were associated with certain kinds of movement. The improvisational, unscripted nature of the creative practice that characterizes making a work of art is a useful lens for viewing everyday life more broadly (Hallam and Ingold 2007). Focusing on artists' own accounts of their work and experience, I hope to show how analysing these two paths alongside one another provides additional insight into the characteristics of each. The points of convergence lead me to a consideration of the importance of movement and imagination as processual and emergent.

Images of movement were often invoked by young Japanese contemporary artists when reflecting on their own creative practices. Their descriptions of the creative process emphasised the processual knowledge involved in the act of creation. Their work was seen as emerging in dialogue with various external influences, materials and challenges, and - perhaps most of all - in creative collaborations. The descriptions which highlighted movement effectively drew attention to the emergent nature, not only of their work, but of their own evolving understanding of questions they had not consciously posed. Imagination is here not a pre-formed image or a precondition for making an artwork, but itself an emergent property of the process of creation. The consideration of the entanglement of the affective and sensory, proposed by the editors of this issue, brings a new force to the study of imagination, as a process that is not merely a mental one, even if it is largely described by my interlocutors as a form of interiority. The task of this article, then, is to attend to the conceptualizations and descriptions of the imaginative process by artists. I argue that imagination can be understood as a "a practice of feeling with the world" (De Antoni and Dumouchel 2017), but a practice that relies both on opening oneself up to the world and a measured disengagement or distancing. In this sense it requires not only a skill of encountering the affordances of objects, a dialogue with the materials, immersing oneself in a flow, but also the effort required to make this possible, a laborious oscillation between immersion and detachment. ${ }^{1}$

In touching upon the affective domain, methodological issues of representation and articulation pose a problem. My own reliance on narrative might be seen to compound this. No 
doubt other methodologies and forms of anthropology, including visual and sensory and anthropology as art, are required to move this work further, but I would like to emphasize that narrative and the statements of the artists - their musings and conversations with me - were my point of departure. Imagination, inspiration, sensation and location of agency in the artistic process emerged from their statements. Affect need not be seen as incompatible with the discursive (Wetherell 2013), and in fact the affective and discursive are often entwined (Wetherell 2013).

Discourse scholar and social psychologist Margaret Wetherell claims that the genealogy of the concept of affect moves many discussions away from discourse as it is precisely understood as that which is extra-discursive, for instance in the work of such scholars as Massumi (2002). She wonders whether the absence of attempts to study the affective and discursive jointly has impeded social research and proposes a study of affective-discursive patterns, a study that builds on affect as an avenue for expanded understanding of social action to include the somatic and that which is not immediately knowable while returning to some of the strengths of methods in discourse studies (Wetherell 2013, 351, 359). In this way she points to the entanglement of affect and meaningmaking. If there is little agreement on the existence of any universal and "basic emotions," neat and easily identifiable units such as anger, fear or sadness, then it might be better to think of affect as a form of social practice, " a flow ... of forming and changing bodyscapes, qualia (subjective states), and actions constantly shifting in response to the changing context. This flow can be categorized, interpreted and parsed in a huge range of subtle and not so subtle ways" (Wetherell 2015: 147, emphasis in the original). From this perspective, it is less then fruitful to fully separate affective practices from the meaning-making and discursive.

Indeed, how should we understand affect when it is channelled into various forms of expression and representation, and further if these expressive acts and objects, such as art, affect others? In certain cases, the social realities that we seek to understand comprise senses, affect and representations which must be discussed alongside one another. For instance, Navaro-Yashin (2012) argues against the complete move away from the representational in discussions of affect, as her research participants on Cyprus insist on various forms of representation:

An environment of ruins discharges an affect of melancholy. At the same time, those who inhabit this space feel melancholic: they put the ruins into discourse, symbolize them, interpret them, politicize them, understand them, project their subjective conflicts onto them, remember them, try to forget them, historicize them, and so on. (ibid., 172).

Her ethnographic material does not allow her to "discard language and subjectivity" (ibid.) and favours affective movements over representation or discourse. This article is a contribution to further exploration of the intersection of the affective/sensory with the representational and the discursive.

Affect and imagination both have an elusive quality that Crapanzano likens to a horizon. What lies beyond on approach recedes further:

Our constructions of the beyond are always slippery. They are, in a sense, like a dream. We experience it, we recall it, but our telling it leaves us with a sense of betrayal, even if 
our telling gives us relief from the anxiety that surrounds it. It is not simply that our words do not do justice to what we dreamed; it is that they change the experiential register (Crapanzano 2010, 21, emphasis mine).

What of those cases when the struggle to capture a dream in words or otherwise, if difficult, is also delightful, or exciting; what if the dream brings us a sensation that we cannot shake off and finds its ways into a story, a painting, dance, or music?

Returning once again to the shores of the river visited by Crapanzano and William James, the frustration that the flow of the river cannot be captured may only worry the scientist, and occasionally the ethnographer. Not all articulation, even if always imperfect and certainly incomplete, is disappointing - the joy of finding or crafting the vessels that one can use, even if only to spill the water or spray it like a child having a bath, can be exhilarating. Responding to this metaphor, my friend Jerry Gordon, an artist long embedded in the Osakan artworld, suggested that sometimes artists tune the flow of the river, by adjusting its dimensions or turning some stones (personal communication 2018). Shifting the experiential register is perhaps exactly the work that some undertake, painstakingly, anxiously, lightly or with joy. Departing from a variety of "practices of feeling with the world" the artists move down their path, at times lightly but often with some effort. To the extent that the imaginative process effects a shift in experiential register, it is also a labor of "feeling with the world."

\section{Finding a way}

The material used to explore these themes is based on fieldwork in Osaka conducted in 2013 with a network of young artists, mostly in their twenties and thirties, involved in a range of contemporary art projects and creative activities. There are many ways to tell a story of creative process in a particular context: to describe in detail the art world (Becker 1982) that it is embedded in and outline the role of the art events that frame it, to attend to a biography of the artist and understand the creative process of making art, to follow a single work of art or a "project" as it moves through different stages, akin to a biography of an object or social life of things (Appadurai 1988), even if it is immaterial; or to focus on experiences of different artists and the similarities and divergences in descriptions of these artists. In this article, the focus is on the last of these, and the analysis draws primarily on the narratives of eight female artists ${ }^{2}$ in their twenties and early thirties, to better focus attention on the similarities and divergences of their lifecourses.

Osaka, as I was reminded repeatedly, is an unusual place to study art production. ${ }^{3}$ It was invariably described as a place where the art market is not particularly well developed, and where little attention is paid to art by the majority of the population as well as by media and local authorities. A person hoping to "make it" as, say, a painter, would need to go to Tokyo, to exhibit there and preferably abroad. They would need to work with a gallery that would take care of their portfolio, and to pay particular attention to the coherence and consistency of their oeuvre, something that most of my interlocutors found constraining. All of them have rejected this form of art work and have decided to stay in Osaka.

Contemporary art production in Japan is often seen as a marginal activity, particularly in comparison with the traditional arts. Moreover, becoming an artist as opposed to a salaried employee is very much considered a non-mainstream lifestyle choice. Many of the contemporary 
artists in Osaka with whom I spoke took this one step further: they rejected the widely recognized path to becoming a "successful" artist, namely affiliating with a gallery and presenting their work in Tokyo and abroad. Rarely able to make a living from art alone, they engaged in other forms of employment and created artwork in the margins of their productive life: that is, in between socially recognized forms of production and reproduction, labour and family life. Some of them were also marginal in terms of their social background (e.g. as members of minority groups), and elected not to create art in clearly defined or recognizable genres. As such, they had few models to look to, both in terms of how to make their art-work, or how to live as an artist.

In a changing world, we cannot always rely on precedents, on steadfastly treading in other people's footprints. As Mary Catherine Bateson $(1989,1)$ has put it: "Each of us has worked by improvisation, discovering the shape of our creation along the way, rather than pursuing a vision already defined." This process of creatively fashioning one's life from the materials at hand rings particularly true for the young artists I spoke to. Indeed, we could say that they were actively engaged in two different but complementary and equally engrossing creative processes: the process of creating an artwork, and the process of composing a life as an artist.

In what follows, I focus on the points of convergence in their varied accounts of their lives and work: specifically, the need to forge a separate sphere for artistic activity; the conditions of creativity; the combination of planning and improvisation in achieving a particular mood or "feel"; the development of ideas via what they termed "moving the hand"; and finally the compulsion to work. All these characteristics of creating a work of art may affect the creative process of composing one's life, both of which unfold in the absence of a predefined plan or script. Furthermore, both of these creative processes do not unfold in isolation, but rather in response to invitations and collaborations with others. Life, like the creative process, rarely refers to clearly defined choices made by an individual, but take place in dialogue and collaboration, with others and with the materials or circumstances in a process of "feeling with the world."

Following a certain life path as an artist, and thereby embodying a particular social role, naturally affects artwork by providing a context for creative endeavour, leading to certain encounters and not others, for instance, or specific collaborations or influences. Conversely, the creative process involved in artistic pursuits, or what we could term art - work, can by its very nature make a specific life-path as an artist inevitable. As the artists themselves often emphasised, the creative process depended not only on carving out a protected space and time for working on artistic products, but also involved a strong urge to keep on working, until one finally sees how what one started working on takes shape "in reality." That is to say, it involved what was often described as a compulsion to keep creating.

\section{Creating a sphere for artistic activity - "There was too much mundane life for the ideas to} emerge."

The key to making art, I was told on numerous occasions, is to have the time. This could be achieved by making a concerted effort to create a space for artistic projects, by choosing jobs that allowed one to dedicate a significant amount of time to artwork. "Time is precious," said Akiko-san, a painter in her early thirties, who had chosen to leave her full-time job in a bank and turned to part-time work as a painting instructor for a private art course. More than the full-time work itself, she 
explained, it was the lack of mental leeway to come up with ideas that made her feel like she was losing the motivation to paint. "[When I worked full-time] the stimuli were too strong, there was so much everyday life (seikatsu ga ippai), from the outside, and the ideas just wouldn't emerge."

A similar sentiment was voiced by Miwa, a painter who had previously worked as a photography editor in a small private business. Despite getting along well with her boss, and not minding the work itself, she grew increasingly discontented and frustrated with everyday interactions with her colleagues. Her predominant feeling was the need to protect a space for artistic work, one which would allow some stimuli from the outside, but would prevent full immersion in the flow of "everyday life." This seemed closely tied with having enough time to dedicate to artistic practice, as well as with the opportunity to allow ideas to come forth. Everyday life was not represented as antithetical to the creative process as such. The problem with "too much everyday life" was not with the mundane, but with "too much" - the demands on one's time and attention or intensity of experience. Occasionally, when "feeling with the world," one feels too much and must step back. Part of the process described by my interlocutors is learning how to discipline these unruly intrusions, or "invasions" of the senses (cf. Seremetakis 1994: 6). If feeling is an active form of engagement with the sensory world, it also involves a measured disengagement.

In some ways, the need to create a sphere for art-work and stepping away from "too much life" refers to the overwhelming quality of the demands of social life and concomitant obligations, as in, for instance, Miwa's case. Thus, not every kind of job was seen as suitable support for art-work. Some of my interlocutors, including Akiko, worked part-time, often in teaching jobs, which were seen as a good way to free up some time. Many were inventive in finding ways to reduce their living expenses in order to work fewer hours. Several worked full-time, but not every kind of profession was seen as equally suitable - sometimes working in a bar was seen as preferable to working in a field such as illustration or design. Kumiko, whose artistic activities ranged from performing poetry to painting and handmade book-making, resigned from a very prestigious and well paid illustration and graphic design job with rather reasonable and flexible working hours, precisely due to its closeness to her own art-work, with design ideas creeping into her own practice in a way she did not find productive. ${ }^{4}$ For several of those involved in the visual arts, graphic design and illustration were seen as the antithesis to what they were striving towards in their own art-work. Akiko even mentioned that despite its fantastical elements, her work is not like that of illustrators, in order to differentiate herself from the dominant art forms of anime and manga, often produced in the context of the animation industry which lead to specific patterns of creative production (Condry 2013; Morisawa 2015). Through necessity or, not infrequently (as the above examples illustrate) by choice, my young interlocutors were outsiders to any large structures of this kind.

\section{Moments of inspiration - "Sometimes sounds just come to me naturally"}

Sora created images or photographs featuring highly artistic make-up and complex wearable objects she designed herself. Most of her projects, she said, originated from thoughts she had when she was alone. Most often this was when she was falling asleep or out on a walk.

I've always lived in a city, so mountains and fields, with many flowers and trees, are a world that feels remote to me. Of course, these places exist but...when I was little I read 
a lot and thought about different worlds. ... The places I think of aren't there, so I need to make them.

As for other artists I spoke to, images come "naturally" in such moments. Take Yumi, a pianist who also plays several other instruments. For the past few years she started mostly performing music she creates herself, in what she described as "half preparation, half improvisation." In her words: "I listen to a lot of music and go to concerts. Sometimes I listen to something and think "I like this, I could do something with this,' and sometimes sounds just come to me naturally."

The description of the working processes of these artists often included some form of raw material, either fragments or vague sensations. While ideas for specific projects often come unexpectedly, my friends were nevertheless actively on the lookout for these materials, some more so than others. Miwa, who painted large canvases in her tiny one-room apartment, told me that she often takes photos when she takes her son out for walks, and on occasion makes clippings from newspapers or fashion magazines. A particular facial expression or a pose might catch her eye:

I see something and I don't paint it there and then, but later I recall a face or a particular atmosphere (fun'iki), a mood (mūdo) that remains. I guess I paint what I remember, [that way] I only take away what I think is important (jūyō). The images that easily stay with me (nokoriyasui), remain.

Memory acts here as a kind of a filter: what Miwa remembers is what is important; only essential elements remain, sometimes just a feel or a mood. The importance of getting the "feel" right was emphasised by all seven of these women.

\section{Feeling around: Planning and improvisation}

Starting with an idea, many then make a plan or draft to convey the right kind of feeling. Akiko makes sketches, and selects the right shape of canvas in order to achieve the right kind of feeling (kanji): a narrow vertical image, for instance, makes the viewer feel like they are looking onto a landscape through a window, or helps convey a confined world; a small canvas might help create an intimate feel, something that Akiko was partly taught to consider and partly learned by thinking how to best achieve a particular effect. Sora thinks of a story or a place she'd like to go but which doesn't exist: in order to see it, she has to make it. She then makes a sketch and tries to stick to it, but often fails in the process. She persists, usually enjoying the challenge. In her attempts, she strives to convey the mood of the place she imagines, to fully convey the feel of the story she has been working with. Such divergence from the plan was seen as risky but also, at times, as inevitable.

The sense of exploration was conveyed well by Etsuko, who made masks and stunning wearable objects: "There's no correct path to making the things I'd like to make, so I have to find my own way." Artists working in fields that are not clearly defined, and which lack a long-standing tradition, are at liberty to explore but also must deal with the challenge of having few set practices or guidelines. They nevertheless all emphasized their interest in trying out new things, and felt undeterred by failure, with a sense of persistence strongly coloring their accounts. Interim failures were reconfigured as challenges, obstacles or encounters which could lead to new discoveries. A real 
failure, in these accounts, occurs when one diverges so much from the idea one had that all sense of direction is lost.

\section{Grasping ideas: 'I move my hand'}

Hitomi sat upright in a red velvet armchair in a downtown Osaka retro café. A striking looking thirtyyear-old painter, she pointed to the thick red tomato juice in her glass:

I could think of red, for instance, then maybe red would be hair, maybe a red-haired woman, perhaps on the floor. I would start drawing and painting and eventually, all kinds of images would get mashed up, layered. So, I wouldn't just paint simply what I thought of [in the beginning] as it is. I really dislike painting like that, I fear that the world would come to a halt... But usually I don't have a concrete idea of I want to express. I move my hand and find it.

This notion of moving one's hand - also mentioned by several others - implies that ideas are not pre-formed in the mind, but take shape in the doing, as the artist "moves her hand":

I think about our human body, how close it is to us. It is very familiar to us and yet we do not understand it, not entirely... So I look at such familiar things, dismantling them, thinking "there is this; here is that." Thinking this way while painting, that is the origin of my imagination (imajinēshon no genten), one could say...

My thinking goes in ebbs and flows, an image emerges, and then another one. I move my hand (te o ugokashite) and then I see it, "oh that is what it is." I guess you could say it is unconscious. Perhaps the things that are inside are realized when I move my hand; as I do it, perhaps the things become clearer.

Then, pausing for thought, Hitomi corrected herself:

Actually, perhaps one could say that, conversely, rather than having ideas inside my head, they spring forth from action (kōdō o okoshitatoki hassei suru).

Similarly, Miwa told me that her best work is rarely based on some big idea - which she has tried but never succeeded at - but instead is achieved when she starts the movement. Literally, the expression Hitomi used in the description above refers to an action; the ideas emerge when the action takes place. In this description, the language becomes more abstract and not even the hand is mentioned. With an intensity of focus, the body that drives the focus, that facilitates the imaginings and the "sensing" recedes into the background, and only the movement remains. Movement resolves many problems one might have if one were to rely on thinking "in the head" alone. It is precisely through moving her hand that Hitomi finds answers to questions she may not have even known she was asking. These answers can be practical, as in the case of Akiko and Etsuko, 
who resolved problems with technique or the right way to express a feeling or mood. On other occasions, as in Hitomi's case, "moving the hand" yields an answer to some question one was grappling with in a broader, sometimes even existential sense. Miwa told me that the only times she finds painting difficult are when she really feels so unwell that she doesn't feel like doing anything at all. But that's precisely the time when, in her opinion, she really should be "moving her hand," in order to get well. Indeed, what she finds most difficult is not painting as such. This brings me to the final point of convergence in these accounts: the urge to work.

\section{The compulsion to work: "I can't settle down till I've seen it"}

The compulsion to work was described forcefully by Etsuko, a designer and painter by education who now makes elaborate and detailed wearable objects based on animals or fantasy worlds: "I think of something, 'ha,' and I make a note of it. Then, I feel like I must make it, or actually, I can't relax until I've made the thing I thought of." Similarly, Sora explained that she feels a pull to make what she had thought of. The world she wants to see isn't there, so she has to make it herself, and is eager to see it in reality. ${ }^{5}$ This compulsion to work is often related to a feeling of unease when one is unable to work: thus, for example, Miwa mentioned that she feels stressed when she cannot find the time to work on her art.

Against the background of their schoolmates and former colleagues disappearing from the art world, the dedication of these women seemed all the more remarkable. All spoke repeatedly of people around them giving up art, having grown too removed from their artistic pursuits as their work or family life took up ever more time. Yet they seemed unwavering in their dedication to their art projects and spoke of how they grew irritable or listless when unable to pursue their interests. This did not obviate the need for discipline and effort: while Miwa insisted she didn't find painting difficult as such, but rather natural like eating or walking, securing time for her work required that she use her time well, for these artistic pursuits are not easy or effortless. It is for this reason that I choose the word "work" when referring to their urge to keep making art - to emphasize the laborious nature of the process, which combines exhilaration of focus with toil and tedium. The body sometimes hurts, its needs forgotten while the focus has its hold over the artist, meals forgotten and shoulders sore. Yet, as a single mother who until recently used to work full-time, Miwa was most irritated by excuses. Paired with this feeling of determination was a strong sense of inevitability: "There is nothing else I can do; painting is the only thing I'm good at." This sense of unease when not working seems to be closely linked with an anxiety about the inability to work, in a broader sense. Hitomi, once told me she fears that she might stop moving her hand. Her first and foremost fear as an artist is not being able to pick up her brush anymore. This young painter, it should be noted, had no intention of abandoning her artistic pursuits and was able to support herself by selling paintings, supplementing her income with specialized illustration work. While she had no intention of changing occupations, she nonetheless feared that she might find herself unable to paint.

On a different occasion, as I already mentioned above, she told me that she dislikes painting things as she sees them, because she worries that the images and thoughts might just stop emerging, that "the world would just stop." The fear described in both instances takes the form of a stoppage, a blockage, a lack of movement - a freezing of the hand or freezing of the world, as some described it: the ultimate fear expressed as an inability to "feel with the world." Similarly, Yumi described the occasional dread of such a blockage on stage, during an improvisation performance, 
expecting to play sounds and no sounds coming to her. Both Hitomi and Yumi never really experienced such moments and they both felt that it was best dealt with precisely by doing, by moving their hands. But neither of them, at this stage in life, felt that they are likely to move away from their artistic pursuits; they both felt they would certainly continue.

Similarly, when speaking of her choice to pursue artistic activities, Akiko expressed a certain sense of resignation. She had tried working at a full-time job in a bank, but she felt that it wasn't right for her, since what she really wanted was to "do paintings":

Lots of my friends are married by now, you know. In my early twenties I worried, of course. I thought I would like to paint, but perhaps I should get a job and work in an office, like everyone else. But it seems I like to paint, so I reconciled myself to it (jibun jishin ni akirameta to iu $\mathrm{ka}$ ), I guess. I want to do paintings, so I better do paintings. ... I used to worry about things like being in harmony with society (shakai to no chōwa) but now I know it's all right.

The life choice of "doing art-work" was seen by all these women as something they felt they "had to" do, lest they grow ever more discontent.

Moving the hand, and the experience of an urge to do art-work, together with a sense of resignation, all cast an interesting light on their sense of authorship. Without doubt, my friends owned their work and saw it as their own doing, but at the same time, they seemed to feel they had no choice. While they see and represent themselves in these accounts as agents, the agency in their description of the creative process is not straightforward. It is inflected by an urge or compulsion to work, by the usual social constraints and conditions from which they have to defend themselves, and it is certainly not always seen to emerge as a consequence of reasoning, from the head, or even the heart. Instead, it is often the hand that moves things along.

\section{The body at work}

Eitsu's hand was moving slowly across the large sheet of copper. The needle made a soft noise in the quiet space of the printmaking studio. The space was still, even though all the seven workstations were occupied. The late October heat was still lingering, slightly uncomfortable, a little incongruent with today's activity - printing of work for the group calendar exhibition the studio organized annually, as part of its winter festivities. They provided high quality paper with an elegant calendar at the bottom and the participating studio members were expected to select or prepare a plate they could present in this group exhibition. The atmosphere was calm and friendly, people working away on their projects individually, but sharing drinks and a sense of purpose, exchanging quiet advice or bits of paint on occasion.

Eitsu was sitting at a large, glass-covered workspace in the middle of the room, cleaning an etching plate which she had carved with flowing strokes of a drypoint needle. Suddenly, she started and got up to her feet - another plate was sitting in a vat of corrosive chemical in the small room next door and now was the time to halt the chemical process, remove the plate and rinse it well. 
Eitsu was wearing a pair of long rubber gloves, oversized for her slender hands and arms. The strong, pungent smell of the chemical saturated the air as she worked. Eitsu took the plate and explained to me that she had added some more detail to a piece she had been working on earlier. The printing presses were both busy, so she told me that she would keep working on the first plate a little longer, adding marks and roughening its surfaces. The light reflected differently in the area she distressed using a tool, while much of the metal had a mellow, soft sheen. She spoke very little, even as we took a break and she offered me some oolong tea. When she was alone, she told me, she often forgot to take breaks, so she liked the days when I was with her and she would remember to drink and eat. It was a kind thing to say, although I was not so sure if she liked dividing her attention like this.

Another day, Eitsu said that she finds work on her prints absorbing and pleasant and told me about how she uses photographs to consider the main lines of the human form she would work with. The plates she used were smooth to the touch and offered only soft resistance to her tools. Printing on a press and trying out the prints in different colors always brought some surprises, she felt, and many parts of the process needed to be broken down into stages, and the waiting was sometimes frustrating and delightful as well for her. She planned her work quite carefully, but the end result depended on the paper, paint consistency and exact mix of colors used, on the minute differences in the time the plate had spent in the vat with the corrosive, on the way the tool caught on the plate. Sometimes others would offer advice or friendly suggestions: "you could try this paint thinner rather than that one." The quiet presence of others and the frame of events were not unimportant. She also entered into a dialogue with the materials and with her tools, but that is when the discourse stops. Indeed, this engagement does not figure in concrete ways in the narratives of the artists I spoke with. The dialogue with their materials is, arguably, a private conversation. That said, if it resisted articulation it was not entirely unexpressed, but was palpable in the work being done. This was precisely the point of the imaginative process, the labor involved in the shift of the experiential register.

The editors of this special issue have not only encouraged us to consider entanglements of affect and the senses, but also to not lose sight of the body - both affect and sensory experiences are embodied, of course. Apart from occasional mentions of the hand, the body is present in the process but largely absent from the narratives of my artist friends and acquaintances. Indeed, like Eitsu, they sometimes forgot the needs of their body, as they moved inward. The body, of course, is still here, sensing and at work, yet its own prompts fall away from view for the time being. Not only external distractions are avoided when immersed in work, even the bodily environment is sometimes tuned out in the move towards the "interior." That said, the sensing instrument does require care, and some of my interlocutors told me that they purposefully tried to look after their bodies, even train or go for a jog or do yoga after working on their art, to balance out their efforts.

\section{Imagination and planning}

The creative process of art-work and composing a life for these young artists have one key thing in common: not working to a script or a predefined model. As such, the imagination here is not best understood as a fully formed image, a vision that guides the process. In lieu of a single, preformed mental image or plan, their descriptions of the creative process emphasised the processual knowledge involved in the act of creation, and in particular the importance of movement of the 
body. In this way they effectively drew attention to the emergent nature not only of their work, but also of their own evolving understanding of questions they had not consciously posed. Imagination is here not a precondition for making an artwork, but is itself an emergent property of the process of creation.

The open-ended quality of imaginative work has been at the core of a number of recent anthropological discussions. In his afterword to a volume on imagination Joel Robbins (2010, 306-7) relates it to freedom. Despite an important acknowledgment that all imagination, reasoning and even perception is culturally inflected, Robbins points out that "the imagination can be understood as relatively more free than perception or reasoning" (ibid., 307, emphasis in original). This kind of freedom, he argues, however conditional or occasionally illusory, nonetheless requires anthropological attention, if it is all that is available to humans. While framing this quality in terms of freedom links it with the ethical domain, other authors attend to the open-ended or underdetermined quality of imagination as its defining characteristic (Sneath, Holbrad and Pedersen 2009, $6)$.

The open-ended quality of imagination need not be understood as an absence of planning and structure. Creating the conditions for art-work, including making the time and space for it, undoubtedly requires planning and effort. Furthermore, the art-work itself requires careful planning, especially when it involves audiences and when that preparation is not taken over by intermediaries or gate-keepers, such as producers or gallerists. All of my interlocutors participated in or even organized small, often underground art events. These events often featured improvisational work, but that does not mean they did not involve planning. Events facilitated interactions, invitations and (often unexpected) collaborations that led to many trans-genre art-works. Events were important, because they often provided an impetus for creating the art-work. Pieces or performances were sometimes created with a specific event in mind and this provided a temporal horizon. The temporality of events provides a different temporal sequencing to that of a "project," which has been described as important in the context of art-making (Sansi 2015).

The format, circumstances and scale of events provided useful constraints that could be seen as conducive to creativity. By the same token, the temporality of events, controlled by the artists themselves, could be seen as providing the freedom that the imaginative moment described by Robbins seems to call for. Temporality at play here is far from politically neutral - at all times people navigate multiple subjective and shared temporal frameworks, but not all of these temporalities have the same social standing and same power (Bear 2014) - dominant temporal framings are far more powerful, such as the one of neoliberal time. The temporality of events, ${ }^{6}$ in this case, affords freedom (in the Robbinsian sense) and yet, by placing some constraints on those engaged in art-work, it allows for some displacement of agency and control.

\section{Agency and authorship}

Art is often discussed in terms of agency, thanks to the enduring legacy of Alfred Gell $(1998,6)$, who sought to understand it as a form of action rather than a symbolic system. For Gell, art objects extend the agency of the maker. In this case, I am interested in the way that artists as makers understand this agency. No doubt they recognized the importance of others in their ideas, expectations, the constraints - material, temporal, social -placed on their work. On many occasions they showed and explained the role of the materials they used, they sought or that were available to 
them, as another important range of factors. In improvisations they entered into a dialogue with materials and with other artists, and at times with the audience, implied in complex affective atmospheres. On the other hand, the ideas of others, expectations and traditions, material and temporal constraints in making, as well as the qualities of the materials used, are important as well.

Interestingly, my interlocutors asserted their authorship of both creative processes: composing a life and making an artwork. And yet, they did not feel fully in charge of either: they felt reconciled, allowing their life path to take shape in response to the compulsions they felt and the need to create space for artistic activity. For the most part, these artists explained their life choices in terms of opportunities that arose, encounters or chance offers from others, rather than representing themselves as purposeful, willing actors.

In a chapter entitled "By the will of others or by one's own action?" Linda Garro writes about volitional control in social life and notes that people at times experience what she calls an "agentic shift" away from themselves. In some contexts, "the feeling that someone else is the willing agent for one's own action may be a desirable outcome," as, for example, for evangelical Christians answering a call from God (Garro 2010, 77). In such a case, actions are not felt to originate from the person performing them, or as a consequence of their own willing.

Might we therefore speak of an agentic shift in the context of the creative process, that of making both an artwork and a life as an artist? Something like the calling of a muse or a divine inspiration in other cultural and historic contexts? In this case, however, the shift is not outwards (like a calling). Action is not seen to originate outside the actor, nor is it merely a consequence of their willing (no matter how much one would will it to be true, one cannot will oneself to make a great artwork). We might say that the source of the action is located "inside" the self, in the interior - somewhat detached or guarded, but not impermeable to the flows of affect and sensation. The creative process here, while relying on collaboration and working with affordances of materials and objects, relies heavily on the creation of a separate sphere, a solitary space of interiority. This is a carefully guarded construct in an active balancing relationship with the collaborative affective atmospheres of the art events. The emphasis my interlocutors placed on interiority does not deny the fact that one is affected by others and the world around one- on the contrary, it is a conscious process of detachment (Candea et al. 2015). I therefore argue that imagination can be seen as a specific case of "feeling with the world" (De Antoni and Dumouchel 2017), one which relies on deliberate severance of certain bonds at certain times, somewhat like "cutting the network" in kin relations (see Strathern 1996). To feel with the world, to attend to the feeling with the world, sometimes one must step away from it to not be overwhelmed when there is too much life around, as Miwa suggested. Imagination, here, is a skilled engagement with the world, and an effort of shifting the experiential register, that is felt as a kind of agentic shift - a move inwards is a move away. This is an interiority which is still somehow separable from the ego, and with the creative process suggesting a path leading to it. Perhaps my friend Tesshu had something like this in mind when we spoke about making a living as an artist. As he put it, citing Basho, while alluding to more than just the precipitous nature of the journey, art is "Oku no hosomichi," a Narrow Road to the Interior.

\section{Notes}


A similar movement has been described by Michel Jackson as an interplay between the "world within and the world without" (2016, 2-3).

This research began in 2013, with a 9-month fieldwork stay in Osaka. I had already become acquainted with several contemporary artists during my fieldwork in 2008 and collaborated with several. The fieldwork comprised gallery visits, participant observation at a range of regular art events and meetings, atelier visits and semi-structured interviews with artists who were a part of a loose network of contemporary artists. Many knew each other and attended each other's events, but they were not part of a firmly structured collective. Whenever possible, video and audio recordings were made, alongside fieldnotes that attended to the affective and sensory (see Pink 2009). In some other ways, Osaka is a good place to study art production outside the major art centres, such as Tokyo or New York. At the same time, it is a major urban centre and has a large and multi-layered art scene and offers multiple opportunities for additional or alternative employment for those artists who cannot or do not wish to make a living from their art-work alone.

Art-work, as discussed earlier, is a form of work. The length of this article does not permit a fuller discussion of labor, employment and work among the contemporary artists in Japan. As creativity is increasingly recognized as an indispensable part of a wide variety of professions, the idea of creativity gains prominence while at the same time growing ever more diluted and vague. Discourses of creativity have become ever more a part of the post-industrial workplace and co-opted in managerial practice, which arguably further redefines "being creative" as implying being self-driven, or an independent problem-solver, or simply "resourceful" (Sansi 2015: 116). Furthermore, in this way workers are encouraged to identify with their job, dissolving the boundary between work and leisure time. Boltanski and Chiapello (2005) thus see art as an example of post-Fordist work par excellence. While prominent current discussions of the experience of the creative process emphasize making (Ingold 2013), I consider art as work in order to emphasize labor. This involves attending to work as effort and as remunerated labour, as a meaningful pursuit and as a career, exploring how it intersects with the life course (Kavedžija forthcoming). In this case, rather than considering art in the context of labor more broadly, I want to focus on imagination as a form of labor of "feeling with the world." 
This compulsion to work is distinct from a more widespread sense that one "ought to be working" or "ought to be seen to be working" - it is not the mere sense that one should be somehow employed and kept busy. Instead it reflects a deep sense of motivation and drive. This sense of drive is, of course, not unique to the Japanese context or to the young Japanese artists, and has been described by psychologists of creativity (Csikszentmihalyi 2009). A more elaborate discussion of events and their temporality is required, but it exceeds the scope of this article.

\section{References Cited:}

Appadurai, Arjun. ed., 1988. The Social Life of Things: Commodities in Cultural Perspective. Cambridge: Cambridge University Press.

Bateson, Mary Catherine. 1989. Composing a Life. New York: Penguin.

Becker, Howard S., 1982. Art Worlds. Berkeley: University of California Press

Candea, Matei, Joanna Cook, Catherine Trundle, and Thomas Yarrow. 2015. "Introduction:

Reconsidering Detachment." In M. Candea, J. Cook, C. Trundle, and T. Yarrow, eds., Detachment: Essays on the Limits of Relational Thinking. Manchester: Manchester University Press, pp. 1-31.

Crapanzano, Vincent, 2004. Imaginative Horizons: An Essay in Literary-Philosophical Anthropology. Chicago: University of Chicago Press.

De Antoni, Andrea and Paul Dumouchel. 2017. "The Practices of Feeling with the World: Towards an Anthropology of Affect, the Senses and Materiality Introduction." Japanese Review of Cultural Anthropology, 18(1), pp.91-98.

Desjarlais, Robert R. and Jason Throop. 2011. "Phenomenological Approaches in Anthropology." Annual Review of Anthropology, 40, pp. 87-102. 
Garro, Linda, 2010. "By the Will of Others or By One's Own Action." In. K. Murphy and C. J. Throop, eds, Toward an Anthropology of the Will, Stanford: Stanford University Press, pp.69-100.

Hallam, Elizabeth and Tim Ingold. 2007. Creativity and Cultural Improvisation. Oxford: Berg.

Hendry, Joy. 2012. Understanding Japanese Society. London: Routledge.

Ingold, Tim. 2013. Making: Anthropology, Archaeology, Art and Architecture. London: Routledge.

Lambek, Michael. 2008. "Value and Virtue." Anthropological Theory, 8(2), pp.133-157.

Massumi, Brian. 2002. Parables for the Virtual: Movement, Affect, Sensation. Durham:

Duke University Press.

Murphy, Arthur E. 1932. "Introduction." In G.H. Mead, Philosophy of the Present, London: Open Court, pp xi-xxxiii.

Murphy. Keith M. and C. Jason Throop, eds., Toward an Anthropology of the Will, Stanford: Stanford University Press,

Nakamura, F., 2007. "Creating or Performing Words: Observations on Contemporary Japanese Calligraphy." In E. Hallam, and T. Ingold, Creativity and Cultural Improvisation. Oxford: Berg. Navaro-Yashin, Yael. 2012. The Make-Believe Space: Affective Geography in a Postwar Polity. Durham: Duke University Press.

Robbins, Joel. 2010. "On Imagination and Creation: An Afterword." Anthropological Forum 2093): 305-313.

Seremetakis, Constantina Nadia. 1994b. "The Memory of the Senses, Part I: Marks of the Transitory." In C. N. Seremetakis, The Senses Still: Perception and Memory as Material Culture in Modernity. Chicago: Chicago University Press, pp. 1-18. 
Sneath, David, Martin Holbraad, and Morten Axel Pedersen. 2009. "Technologies of the Imagination: An Introduction." Ethnos, 74(1): 5-30.

Strathern, Marilyn. 1996. "Cutting the Network." Journal of the Royal Anthropological Institute, 2(3): 517-535

Wetherell, Margaret. 2013. "Affect and Discourse-What's the Problem? From Affect as Excess to Affective/Discursive Practice." Subjectivity, 6(4): 349-368.

Wetherell, Margaret. 2015. Trends in the Turn to Affect: A Social Psychological Critique. Body \& Society 21(2):139-166.

Wilf, Eitan. 2012. "Rituals of Creativity: Tradition, Modernity, and the "Acoustic Unconscious" in a US Collegiate Jazz Music Program. American Anthropologist, 114(1): 32-44. 